\title{
REDISTRIBUIÇÃO DAS ATIVIDADES DOS ASSISTENTES TÉCNICOS ADMINISTRATIVOS E O IMPACTO NAS HORAS EXCEDENTES EM UNIDADE BÁSICA DE SAÚDE
}

AUTORES: Danielle Viana Ribeiro Ramos; Elaine Ribeiro do Amaral; Natalia T. Goncalves Brito; Vanessa Aparecida G. Santos; Vanessa Maria A. dos Santos; Aline Marion Moreira K. Miranda; Adriene R. Arcos; Valéria Andrade Lopes; Macilene de Lima Silva.

\section{INTRODUÇÃO}

Hospital Israelita Albert Einstein

As atividades do assistente técnico administrativo (ATA) fazem parte da rotina das Unidades Básicas de Saúde (UBS) são reconhecidas como imprescindíveis no processo de trabalho desses serviços. O desequilíbrio na distribuição das atividades administrativas, pode acarretar às instituições um excesso de horas trabalhadas, levando a uma sobrecarga de trabalho dos profissionais e aumento dos custos relacionados à afastamentos e horas excedentes. A UBS Alto do Umuarama possui 8 ATAS com uma carga horária de 200h/ semanais. Um problema enfrentado pela gestão foi o acúmulo de banco de horas e horas excedentes desses profissionais em 2017, gerando $368 \mathrm{~h}$ de banco de horas, equivalente a quase 2 meses de trabalho e 141 horas excedentes, equivalente a quase 1 mês de trabalho.

\section{OBJETIVO}

Medir o tempo gasto nas atividades e gerar um gráfico de balanceamento operacional (GBO) dos (ATAs).

\section{MÉTODO}

Trata-se de um estudo realizado por meio da metodologia Lean Six Sigma (Change Belt) onde as medições foram realizadas (Janeiro à Agosto 2017) em um instrumento para indicar o tipo, frequência e tempo gasto nas atividades e divididas em semanas por termos atividades diferentes de acordo com a semana.

\section{RESULTADO}

Com as ações implementadas (matriz de habilidade, revisão e geração de gráfico de balanceamento das atividades, ocorreu nos primeiros 3 meses de implementação das melhorias uma redução em $20 \%$ do número de banco de horas e de $100 \%$ o número de horas excedentes.
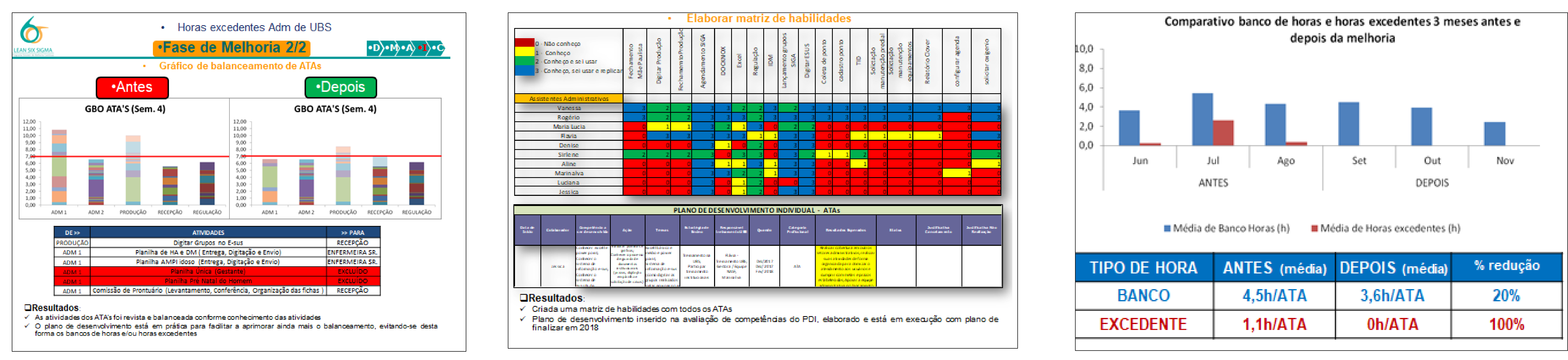

\section{CONSIDERAÇÕES FINAIS}

A metodologia Lean Six Sigma apoiou a gestão na distribuição de forma equalizada das atividades entre os ATAs, com impacto na redução do número de horas excedentes e banco de horas.

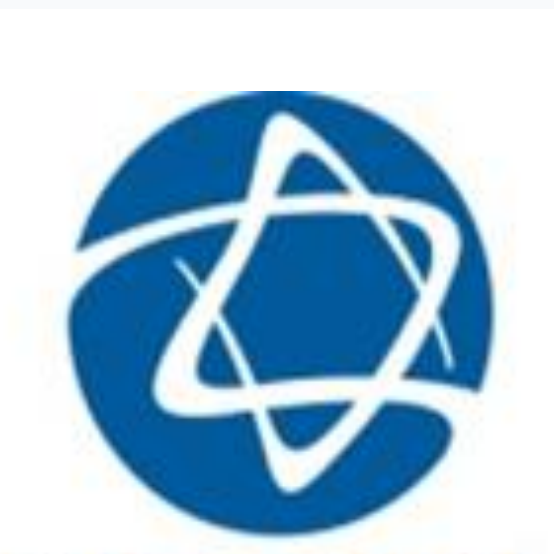

ALBERT EINSTEIN

Sociedade BENEFICENTE ISRAELITA BRASILEIRA

\section{sush} SAÚDE 